\title{
Efficacy and safety of adenosine in the treatment of supraventricular tachycardia in infants and children
}

\author{
JANICE TILL, * ELLIOT A SHINEBOURNE, * MICHAEL L RIGBY, * \\ BERNARD CLARKE, $\dagger$ DAVID E WARD, $\ddagger$ EDWARD ROWLAND $\dagger$
}

From the Departments of ${ }^{\star}$ Paediatric Cardiology and $†$ Cardiology, Brompton Hospital and the $\ddagger$ Department of Cardiological Sciences, St George's Hospital, London

SUMMARY One hundred and seventeen episodes of supraventricular tachycardia in 50 children, including 28 infants, were treated with intravenous adenosine. Adenosine was prepared in a sterile solution of $0.9 \%$ saline $(1 \mathrm{mg} / \mathrm{ml})$ and given in incremental doses of $0.05 \mathrm{mg} / \mathrm{kg}$ every two minutes to a maximum of $0.25 \mathrm{mg} / \mathrm{kg}$. Ninety of the 117 episodes were terminated. This included 88 of the 102 episodes of junctional tachycardia (79 of the 92 episodes of atrioventricular reentry tachycardia, seven of the eight episodes of atrioventricular nodal reentry tachycardia, and both of the episodes of long R-P' tachycardia). Only one of four episodes of His bundle tachycardia and one of the eight episodes of ectopic atrial tachycardia were terminated. None of the three episodes of atrial flutter were terminated. Side effects were frequent but mild and included transient complete atrioventricular block ( $<6 \mathrm{~s}$ ), sinus bradycardia $(<40 \mathrm{~s})$, ventricular extrasystoles, flushing, nausea, headache, and respiratory disturbance. Reinitiation (within $5 \mathrm{~s}$ ) of supraventricular tachycardia occurred in 13 of the terminated episodes.

Although reinitiation limited its clinical efficacy in some patients, intravenous adenosine offered a safe and efficient method of rapid termination of most episodes of supraventricular tachycardia and in some cases facilitated diagnosis of the mechanism.

Adenosine is a short-acting purine nucleoside with the potential to slow conduction through the atrioventricular node and suppress the automaticity of atrial and Purkinje tissues. It has been used successfully for treatment and diagnosis of adults ${ }^{1}$ and seems to compare favourably with more traditional agents. ${ }^{2}$ We have followed up a preliminary report on its use in infants and children. ${ }^{3}$

\section{Patients and methods}

One hundred and seventeen episodes of supraventricular tachycardia in 50 children $(29$ male and 21 female; aged one day to 17 years (median two months) were treated with adenosine. Twenty eight were under one year of age. The results in four of the children were reported in an earlier preliminary communication. $^{3}$

In most, the mechanism of tachycardia was diag-

Requests for reprints to Dr Janice Till, Department of Paediatric Cardiology, Brompton Hospital, Fulham Road, London SW3 6HP.

Accepted for publication 17 March 1989 nosed from the surface electrocardiogram. The criteria used included the relation of the $P$ wave to the QRS complex, the $P$ wave axis, and the presence or absence of QRS alternans during tachycardia." In some children recordings from temporary oesophageal or epicardial (after surgery) electrodes were used to assist diagnosis. Seven children underwent a full electrophysiological study by standard methods.

Twenty eight children had atrioventricular reentry tachycardia (overt pre-excitation in 12, concealed in 16), eight had atrioventricular nodal reentry tachycardia, one incessant long $\mathbf{R}-\mathbf{P}^{\prime}$ tachycardia, three His bundle tachycardia, three atrial flutter, and eight ectopic atrial tachycardia. One child had both His bundle tachycardia and atrial flutter on two different occasions; both were treated with adenosine. Twenty seven children had a structurally normal heart. Table 1 shows the anatomical details of the other 23.

In most children vagal manoeuvres and other forms of standard treatment had been tried unsuccessfully. One hundred and thirteen of the 117 episodes of supraventricular tachycardia occurred spontaneously. The other four episodes of tachycar- 
Table 1 Data on children with structural abnormalities of the heart

\begin{tabular}{llll}
\hline Anatomical diagnosis & Operation & Arrhythmia & No of children \\
\hline TGA & Mustard & AVRT & 2 \\
& & HBT & AFI \\
& Arterial switch & AVNRT & $2 \star$ \\
& EAT & 2 \\
TGA plus pulmonary stenosis & Senning & AFI & 1 \\
Ebstein's anomaly & Blalock shunt & EAT & 1 \\
Common arterial trunk & Correction & AVRT & 1 \\
Tetralogy of Fallot & - & HBT & 1 \\
Aortic stenosis & Valvotomy & AVNRT & 1 \\
AV, VA discordance, pulmonary atresia & Blalock & EAT R-P' & 1 \\
Idiopathic dilated right atrium & - & AVRT & 1 \\
VSD, subaortic stenosis & Closure VSD, & 1 \\
DILV & resection of muscle bar & AVRT & 1 \\
Hypoplastic left heart & Fontan & EAT & 1 \\
Myocardial necrosis of unknown origin & Norwood (1st stage) & AVNRT \\
Multiple tumours & - & HBT & 1 \\
\hline
\end{tabular}

* One child had both atrial flutter and His bundle tachycardia.

AVRT, atrioventricular reentry tachycardia; AVNRT; atrioventricular nodal reentry tachycardia; HBT, His bundle tachycardia; EAT, ectopic atrial tachycardia; AFI, atrial flutter; TGA, transposition of the great arteries; VSD, ventricular septal defect; DILV, double inlet left ventricle.

dia were induced during electrophysiological study.

Adenosine was prepared as a sterile solution in $0.9 \%$ sodium chloride $(1 \mathrm{mg} / \mathrm{ml})$. The initial dose was $0.05 \mathrm{mg} / \mathrm{kg}$ given intravenously. This was increased in increments of $0.05 \mathrm{mg} / \mathrm{kg}$ to a maximum dose of $0.25 \mathrm{mg} / \mathrm{kg}$ or until termination was achieved. Each bolus was flushed immediately with physiological saline. The electrocardiogram was recorded throughout administration of the drug. Blood pressure was monitored immediately before and immediately after each bolus either by sphygmomanometer or by direct intra-arterial measurement.

Children receiving other antiarrhythmic drugs were included in the study, as were 20 children in overt cardiac failure, eleven of whom required inotropic agents to maintain a satisfactory blood pressure. Children were excluded from the study if they were asthmatic (or had a strong family history of asthma) or if they had a history of complete atrioventricular block.

One child received an infusion of adenosine in an attempt to control a postoperative His bundle tachycardia. This was tried when an intravenous bolus unexpectedly resulted in successful transient termination of the tachycardia. The infusion was given into the right internal jugular vein. A dose of $0.05 \mu \mathrm{g} / \mathrm{kg} / \mathrm{min}$ was given initially and increased in stages to a maximum dose of $0.3 \mu \mathrm{g} / \mathrm{kg} / \mathrm{min}$. Heart rate and blood pressure were monitored continuously-blood pressure through an indwelling intraarterial cannula in the femoral artery and a catheter in the pulmonary artery.

\section{Results}

Ninety (77\%) of the 117 episodes of supraventricular tachycardia were terminated (table 1). Collectively $88(86 \%)$ of the 102 episodes of junctional tachycardia (that is atrioventricular reentry tachycardia, atrioventricular nodal reentry tachycardia, and long R-P' tachycardia) were terminated and $79(86 \%)$ of the 92 episodes of atrioventricular reentry tachycardia. Analysis of the surface electrocardiogram recorded during termination confirmed that the mode of termination was a block in the atrioventricular nodal limb of the reentry circuit in most cases. In six episodes termination resulted from a block in the accessory pathway (fig 1 ) in four infants previously treated with class 1 drugs (flecainide and disopyramide) who still had appreciable blood concentrations of these agents and in two children who had received no other antiarrhythmic drug. Seven of the eight episodes of atrioventricular nodal reentry tachycardia were terminated by adenosine. Only one of these episodes occurred during an electrophysiological study and on this occasion termination was the result of slowing in the slow anterograde limb of the circuit. The long $R-P^{\prime}$ tachycardia terminated in the retrograde limb of the reentrant circuit on two occasions. Only one each of the four episodes of His bundle tachycardia and of the eight episodes of ectopic atrial tachycardia were terminated by adenosine. No episodes of atrial flutter were terminated, but transient slowing of the ventricular rate resulted from an increased degree of atrioventricular nodal block (fig 2). 
206

Till, Shinebourne, Rigby, Clarke, Ward, Rowland $\stackrel{\oplus}{乛}$

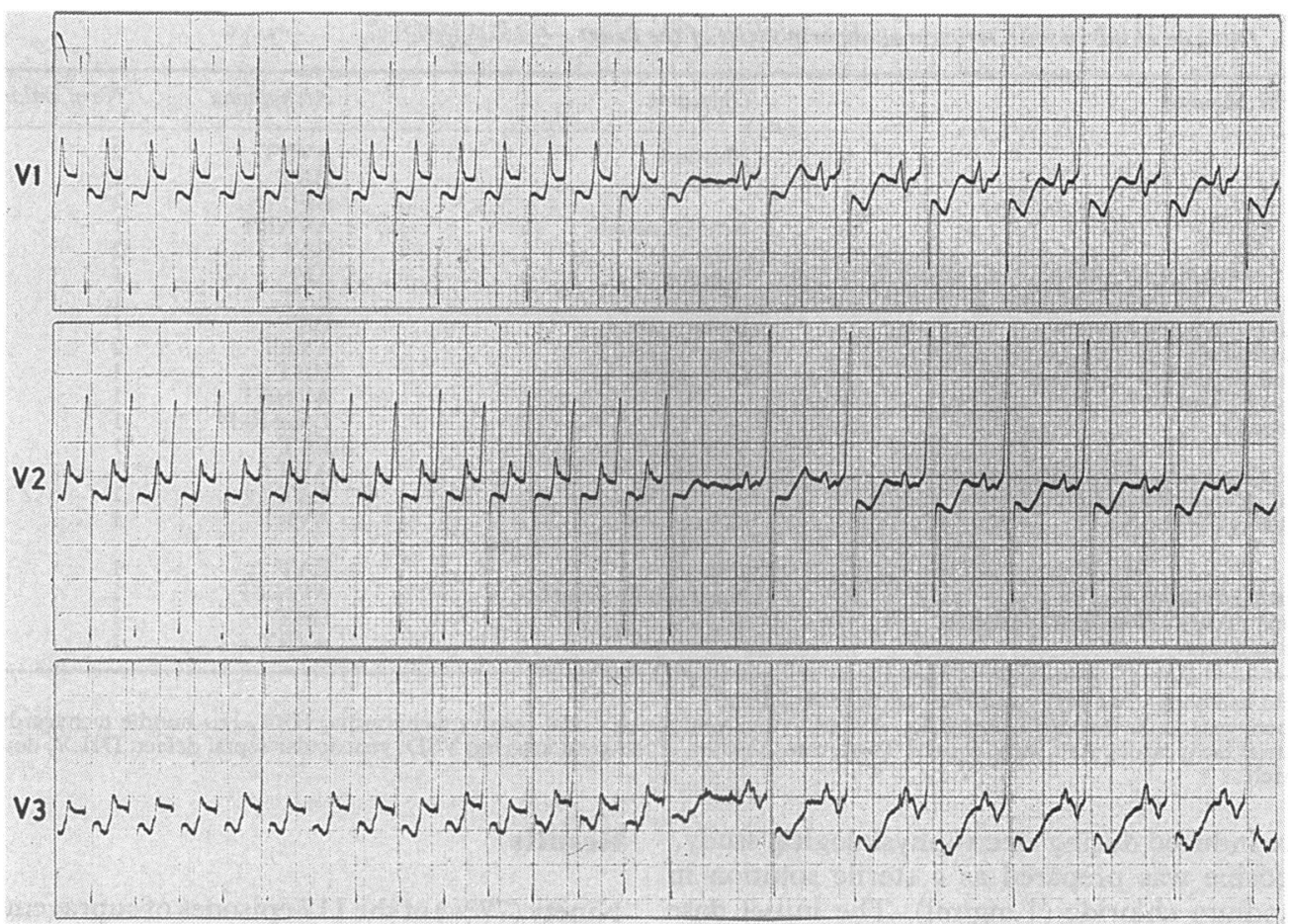

c.

Fig 1 Termination of orthodromic atrioventricular reentry tachycardia in the retrograde limb of the reentry circuit after infusion of intravenous adenosine in a neonate receiving oral flecainide. Paper speed $25 \mathrm{~mm} / \mathrm{s}$.

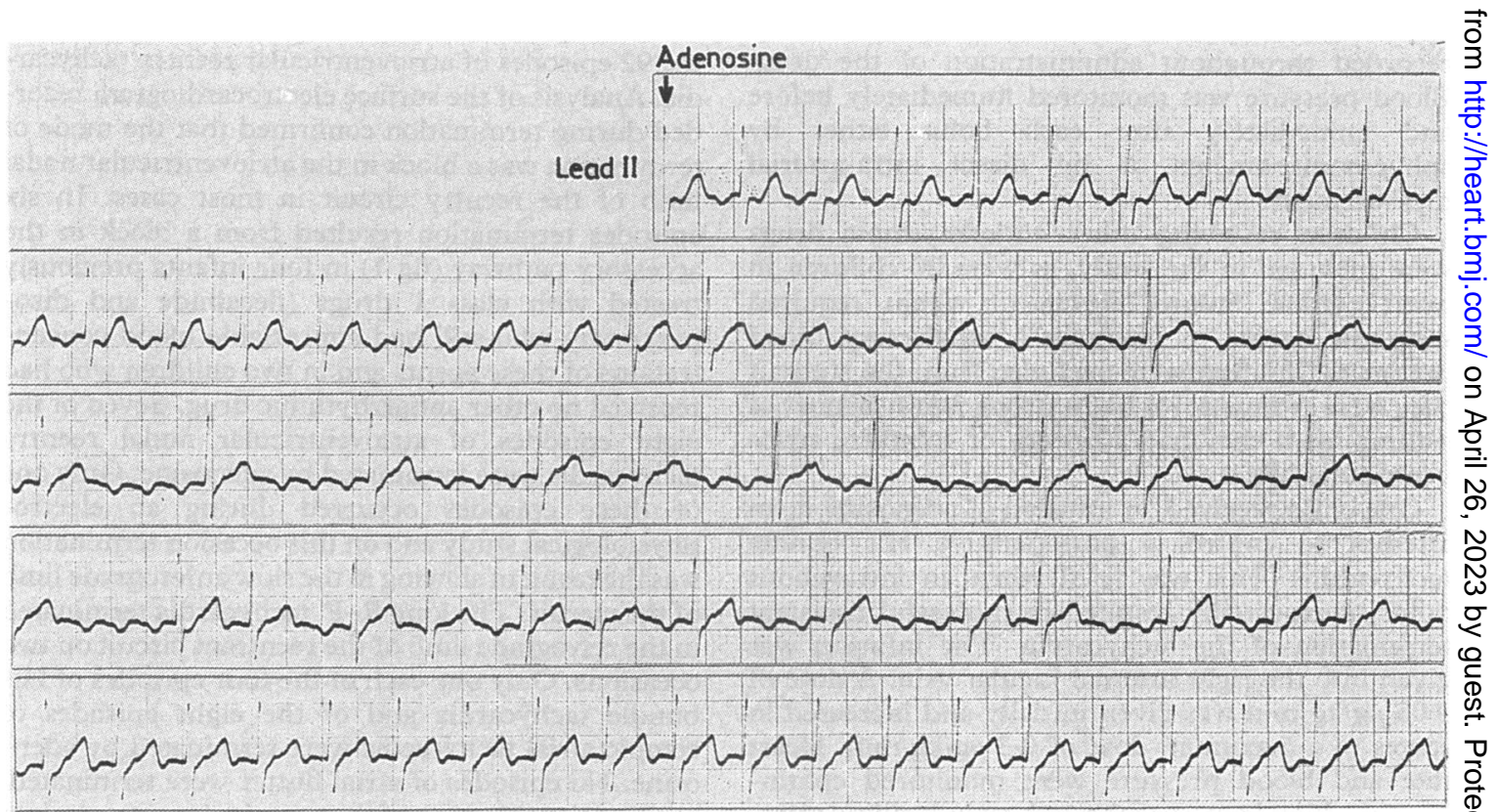

Fig 2 A continuous electrocardiogram showing the effects of adenosine in an infant with atrial flutter. Transient slowing of atrioventricular nodal conduction reveals flutter waves on the surface electrocardiogram. Paper speed $25 \mathrm{~mm} / \mathrm{s}$. 
Adenosine produced a rapid conversion to sinus rhythm in those patients in whom it was effective; the time to termination ranged from 6 to $20 \mathrm{~s}$ (median $12 \mathrm{~s})$. This was noticeably shorter if the agent was administered into a central vein rather than peripherally. The dose required ranged from $0.05 \mathrm{mg} / \mathrm{kg}$ to $0.25 \mathrm{mg} / \mathrm{kg}$ (median $0.15 \mathrm{mg} / \mathrm{kg}$ ). Many of the 50 children (117 episcdes) were given adenosine on more than one ociasion. Eight children received adenosine on more than two occasions. In these we were able to make some assessment of the variation in the response within individual patients. In general, adenosine either worked every time or failed repeatedly, and in those in whom it was successful a very similar dose could be used on each occasion. The administration of other oral drugs, however, often changed the response to adenosine.

\section{COMPLICATIONS}

There were no important complications after an intravenous bolus of adenosine in our patients but relatively mild and unsustained side effects were common. A transient disturbance of respiration and flushing were common but not distressing. One child complained of nausea and headache. One infant, who was inadvertently given a maximum dose of adenosine as the first dose, experienced a sinus bradycardia of $\mathbf{4 0}$ beats per minute after termination, but the heart rate returned to normal within $40 \mathrm{~s}$. In a further two patients transient complete atrioventricular block developed immediately after termination but this resolved within $6 \mathrm{~s}$ (fig 3). After a Mustard procedure in a child who before the onset of supraventricular tachycardia had long episodes of junctional rhythm, termination was followed by a junctional escape rhythm. Ventricular couplets and ventricular extrasystoles were seen in six children but were not responsible for termination of tachycardia in any. No patient had atrial fibrillation or chest pain and no intervention was required for these shortlasting complications. We did not detect a fall in blood pressure after an intravenous bolus in any patient; instead blood pressure tended to increase after reversion to sinus rhythm.

In patient 16 with $\mathrm{His}$ bundle tachycardia, transient termination was achieved with a bolus of adenosine $(0.2 \mathrm{mg} / \mathrm{kg})$. The arrhythmia had developed two hours after complete repair of common arterial trunk and gave rise to a low cardiac output requiring support with high doses of catecholamines. The child was receiving anaesthetic drugs to suppress activity and assist ventilation at this time. The infusion of adenosine resulted in a fall in heart rate from 224 to 207 beats per minute but was accompanied by a fall in both systolic (maximum fall $29 \mathrm{~mm} \mathrm{Hg}$ ) and diastolic (maximum fall $10 \mathrm{~mm} \mathrm{Hg}$ ) blood pressure. All variables returned to normal within 15 seconds of the end of the infusion. This was the only child in whom blood pressure fell.

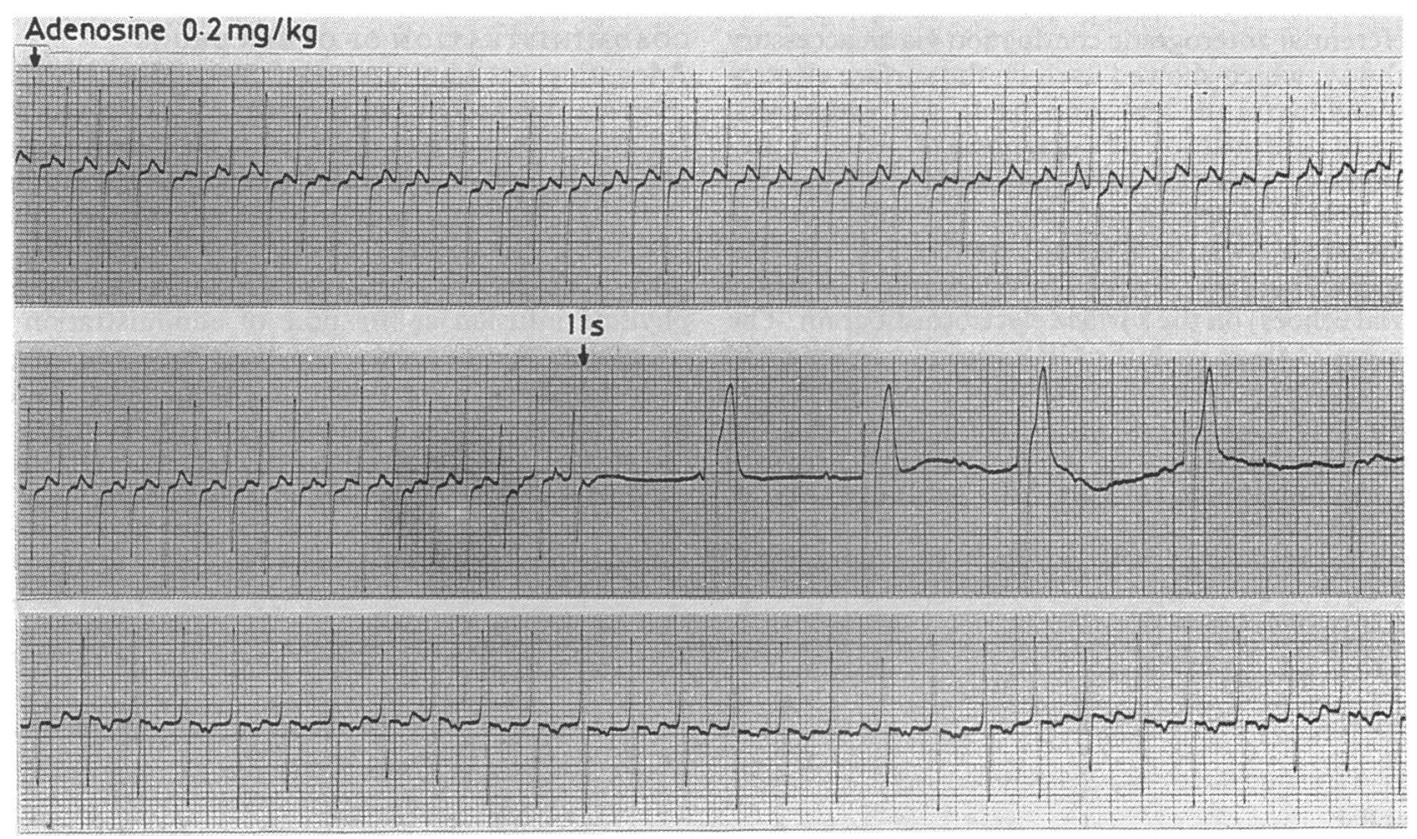

Fig 3 Transient complete atrioventricular block after termination of atrioventricular nodal reentry tachycardia. Continuous rhythm strip lead V2. Paper speed $25 \mathrm{~mm} / \mathrm{s}$. 


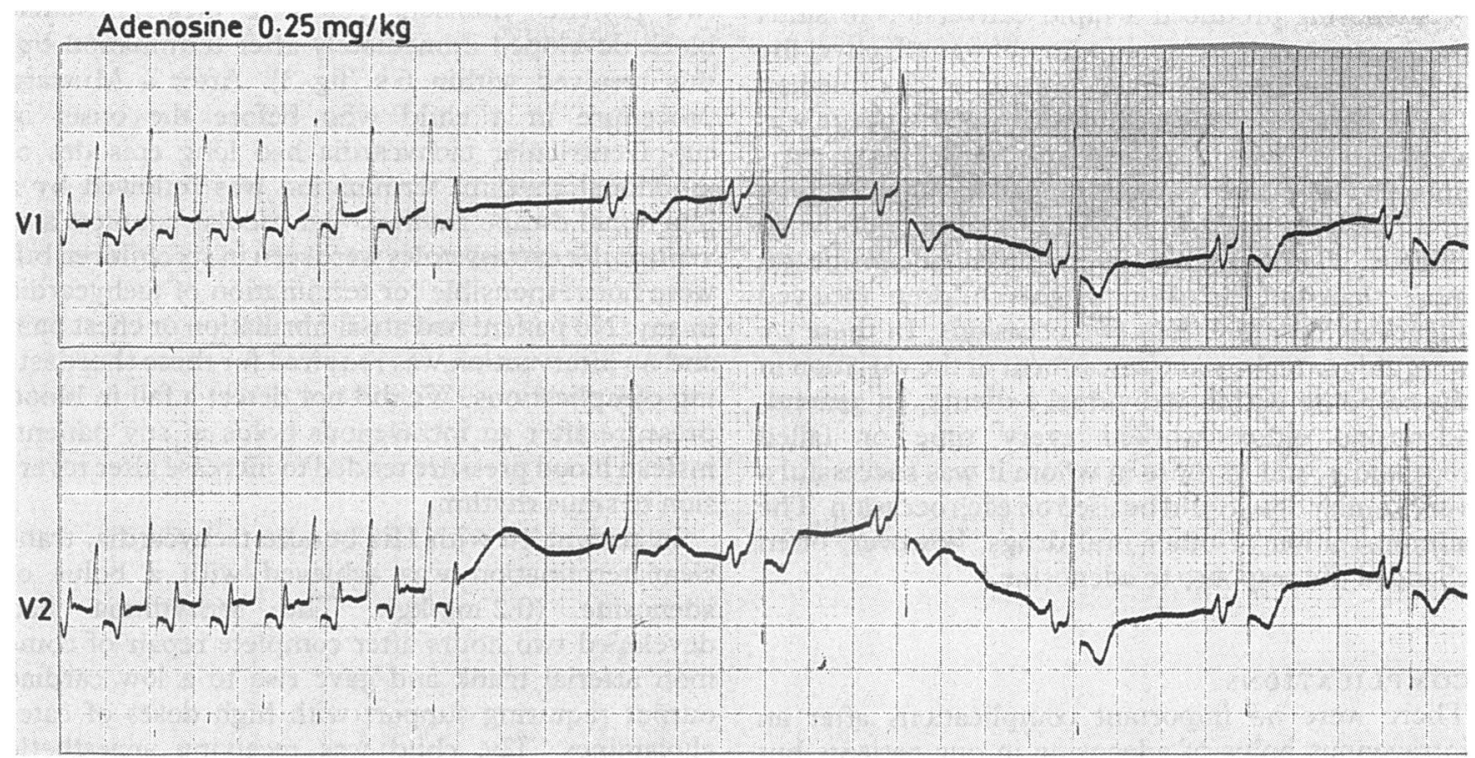

Fig 4 Termination of orthodromic atrioventricular reentry tachycardia in the atrioventricular nodal limb of the reentry circuit after adenosine. Transient pre-excitation can be seen after termination in this neonate with "latent" Wolff-ParkinsonWhite syndrome. Paper speed $25 \mathrm{~mm} / \mathrm{s}$.

\section{ROLE IN DIAGNOSIS}

In eight children with "concealed" pre-excitation and atrioventricular reentry tachycardia, termination of the arrhythmia was followed by a transient delay in atrioventricular nodal conduction. This allowed preferential anterograde conduction via an accessory pathway, which showed itself on the surface electrocardiogram for the first time (fig 4). Thus adenosine allowed confirmation of a diagnosis of "latent" preexcitation and atrioventricular reentry tachycardia. Similarly in nine children, after termination of the tachycardia, ventriculoatrial conduction via the accessory pathway resulted in "retrograde" $P$ waves (atrial echoes) on the surface electrocardiogram. The relation of these with the QRS complex again aided the diagnosis of the mechanism of supraventricular tachycardia. In two of the three episodes of atrial flutter the mechanism of supraventricular tachycardia was not appreciated until the administration of adenosine, but because adenosine caused a transient delay in the conduction of the atrioventricular node, flutter waves could be seen clearly on the surface electrocardiogram-thus establishing the diagnosis.

\section{COADMINISTRATION OF OTHER DRUGS}

Adenosine was administered to 20 children who had received digoxin in the previous 24 hours, to five children who still had therapeutic concentrations of amiodarone, to five children undergoing treatment with oral flecainide, and to two receiving oral disopyramide. No adverse effects were seen in any of them. One patient was already receiving an aminophylline infusion at the time of administration of adenosine. We had expected that this child might have required a higher dose of adenosine for termination because aminophylline is known to compete at cell surface receptors'; however, conversion to sinus rhythm was achieved with a dose of $0.05 \mathrm{mg} / \mathrm{kg}$.

Table 2 Results of adenosine infusion in 50 infants and children with supraventricular tachycardia

\begin{tabular}{|c|c|c|c|c|}
\hline Arrhythmia & No of children & No of episodes & $\begin{array}{l}\text { No of episodes } \\
\text { successfully terminated }\end{array}$ & $\begin{array}{l}\text { Sustained } \\
\text { termination }\end{array}$ \\
\hline $\begin{array}{l}\text { AVRT } \\
\text { AVNRT } \\
\text { EAT } \\
\text { HBT } \\
\text { AFI } \\
\text { Long R-P' }\end{array}$ & $\begin{array}{r}28 \\
8 \\
8 \\
3 \\
3 \\
1\end{array}$ & $\begin{array}{r}92 \\
8 \\
8 \\
4 \\
3 \\
2\end{array}$ & $\begin{array}{l}79(86 \%) \\
7(87 \%) \\
1(12 \cdot 5 \%) \\
1 \\
0 \\
2\end{array}$ & $\begin{array}{l}71(77 \%) \\
6(75 \%) \\
0 \\
0 \\
0 \\
0\end{array}$ \\
\hline
\end{tabular}

See footnote to table 1 for abbreviations. 


\section{REINITIATION}

Rapid reinitiation of supraventricular tachycardia was seen in 13 of the 90 episodes terminated by adenosine. This occurred in four tachycardias known to be incessant (long $\mathbf{R}-\mathbf{P}^{\prime}$, His bundle tachycardia, and ectopic atrial tachycardia) but also in nine episodes of paroxysmal tachycardia. Sustained termination was therefore achieved in $66 \%$ of all cases (75\% of all episodes of junctional tachycardia-that is $\mathbf{7 7} \%$ of atrioventricular reentry tachycardia, $\mathbf{7 5 \%}$ of atrioventricular nodal reentry tachycardia, and none of the episodes of His bundle tachycardia or ectopic atrial tachycardia).

\section{Discussion}

Adenosine is a purine nucleoside with a half life in humans of $<15 \mathrm{~s}$. The full role of endogenous adenosine remains to be elucidated. It may be an important regulator in many systems. ${ }^{6}$ In vitro, adenosine depresses the conduction of the atrioventricular node and the automaticity of the atrial and Purkinje fibres, hyperpolarises the membrane, and shortens the action potential of atrial myocytes. ${ }^{7}$ These actions may be used to terminate attacks of supraventricular tachycardia, and the related compound adenosine triphosphate has been used in such a way for many years. ${ }^{89}$ It has recently become clear that many of the actions of adenosine triphosphate result from its rapid breakdown to adenosine. There is some evidence to suggest that some actions of the two compounds are mediated by different purinergic receptors, ${ }^{10}$ and indications that side effects may be worse with adenosine triphosphate ${ }^{11}$ have prevented its widespread acceptance.

The success of both these agents in the termination of junctional tachycardia lies in their ability to interrupt the critical timing necessary for continuation. In our series adenosine proved highly effective in these arrhythmias, with an immediate termination rate of $\mathbf{8 6 \%}$. In atrioventricular reentry tachycardia delay within the circuit occurred predictably in the atrioventricular nodal limb in most cases.

Termination of orthodromic atrioventricular reentry tachycardia in the retrograde limb of the circuit was an intriguing and unexpected finding because adenosine has little direct action on myocardial tissue in vitro. Possible explanations are that the accessory pathways in such young patients have different physiological properties and are sensitive to adenosine or that the accessory pathway is sensitised to the effects of adenosine by prior treatment with class 1 drugs. Overholt and colleagues also saw this phenomenon in a few of the children they treated with adenosine $^{12}$ but as they suggested, without intracardiac recordings, it is impossible to exclude the possibility of an accessory pathway with decremental (atrioventricular nodal) properties on the basis of the electrocardiogram alone, even though the surface electrocardiogram during tachycardia was not typical of such a tachycardia. Similarly, we suggest that it is not possible to exclude the induction of atrial extrasystoles, by adenosine, which are blocked, and therefore not manifest on the surface recording, but which would effectively terminate a reentry tachycardia.

Adenosine was not as successful with other types of arrhythmia, confirming the findings of Overholt and colleagues. ${ }^{12}$ Perelman and Krikler recently reported a case in which ectopic atrial arrhythmia was terminated by adenosine triphosphate and they suggested this agent may act directly on the atrial myocytes. ${ }^{13}$ In one patient in whom there was an automatic focus of atrial tachycardia in our series adenosine was successful. Although adenosine was seldom effective in terminating these arrhythmias, the disclosure of continuing tachycardia in the presence of variable degrees of transient atrioventricular block was useful in diagnosis. Three of the four patients with His bundle tachycardia were resistant to treatment although a fourth was terminated transiently, prompting a trial of continuous adenosine infusion. Importantly, adenosine did not cause the acceleration that may be seen when verapamil is used in such a tachycardia.

We report the results of an open trial of the use of adenosine. This was not a comparative study. None the less, many of the patients had not responded to more conventional drugs given before adenosine. For many years digoxin has been regarded as the best drug to treat supraventricular tachycardia in childhood and particularly in infancy. Unlike most other agents it is not negatively inotropic and thus may be administered safely when arrhythmias are complicated by severe impairment of cardiac output. However, its use is not without complications and more recently its efficacy has been questioned. ${ }^{14}$ Because there may be a considerable delay before termination is achieved it is possible that termination is spontaneous rather than the result of a direct drug action; and at an arbitrary time limit of two hours its efficacy is estimated to be less than that of other agents (71\% digoxin, $87 \%$ adenosine triphosphate, $93 \%$ verapamil). ${ }^{15}$ Digoxin can enhance the development of arrhythmias after direct current countershock, and when it is given to treat ventricular tachycardia mistakenly diagnosed as supraventricular tachycardia it can cause ventricular fibrillation. Verapamil has been shown to be highly effective in the short term treatment of supraventricular tachycardia ${ }^{16}{ }^{17}$ but is contraindicated in the presence of myocardial disease, recent treatment with $\beta$ block- 
ers, and sick sinus syndrome. In recent reports the efficacy of both adenosine and adenosine triphosphate compared favourably with that of verapamil. ${ }^{18}$ Undoubtedly some of the problems reported with verapamil in children have been secondary to its inappropriate use ${ }^{19}$ but some have suggested profound collapse of infants under one year of age after intravenous verapamil. ${ }^{2021}$ It has been speculated that this may be the result of increased sensitivity to verapamil in young patients. ${ }^{22}$ In addition, like digoxin, if verapamil is given mistakenly during ventricular tachycardia it may result in ventricular fibrillation and may cause acceleration of a His bundle tachycardia. ${ }^{23}$ It seems from our work and that of Griffith et alt that adenosine may be safely given in both these circumstances.

Side effects with adenosine were common during treatment but they were acceptable because they were transient. We attempted to exclude children with sick sinus syndrome because we anticipated the effects of adenosine on sinus node automaticity. Two children who had undergone a Mustard procedure and later developed sinus node dysfunction, however, were admitted to the study. No adverse effects were seen in these patients. This is in contrast with the findings of Overholt and his colleagues who included in their trial one child with diffuse disease of the conduction system and found a prolonged sinus bradycardia without an adequate escape rhythm after adenosine. ${ }^{12}$ They suggested that children with underlying dysfunction of the sinus or atrioventricular node should be treated with caution because their patient needed temporary ventricular pacing.

The children with impaired cardiac output, including those receiving catecholamine infusions, showed no sustained fall in blood pressure after an intravenous bolus of adenosine, and yet an infusion of adenosine in one patient resulted in a fall in both systolic and diastolic blood pressure. Because of these seemingly conflicting results it is worth discussing the effects of adenosine on the cardiovascular system, as far as they are known. Adenosine is a potent vasodilator, acting through specific vascular receptors and this effect is seen in anaesthetised patients and used to produce controlled hypotension during neurosurgical procedures. ${ }^{25}$ In conscious individuals, however, this vasodilator action is not usually manifest. In a recent study by Biaggioni et al a bolus of adenosine in conscious adult volunteers resulted in a biphasic blood pressure response with an initial increase in both systolic and diastolic pressure at 27 seconds followed by a fall approximately 10 seconds later. ${ }^{26}$ This fall in pressure (maximum $9 \mathrm{~mm} \mathrm{Hg}$ systolic and $12 \mathrm{~mm} \mathrm{Hg}$ diastolic) was accompanied by an increase in heart rate. An infusion of adenosine in the same volunteers
Till, Shinebourne, Rigby, Clarke, Ward, Rowland $\stackrel{\mathbb{1}}{7}$ resulted in a dose dependent increase in heart rate $\stackrel{c}{\Rightarrow}$ with little change in mean blood pressure. The same $\stackrel{\vec{S}}{\overrightarrow{3}}$ group then studied adults with autonomic failure and $\overline{0}$ found quite different results in that a bolus dose of $\frac{}{5}$ adenosine resulted in a fall in blood pressure and $\frac{\bar{c}}{\frac{5}{a}}$ bradycardia. They concluded that the masking of the $\stackrel{\mathbb{Q}}{\propto}$ direct vasodilator effects of the agent in conscious patients results from an autonomic reflex possibly mediated by chemoreceptors in the carotid body. After a similar dose of adenosine, we did not detect a $\vec{\omega}$ fall in blood pressure, whether or not the children o were receiving anaesthetic drugs. However, this may reflect the inaccuracies of our method, because in os most children blood pressure was measured with a $\omega$ sphygmomanometer rather than by direct intra- i arterial cannulation, and there was usually a short $\AA$ delay before the measurement could be taken. $A$ 음 transient increase in heart rate after termination was $\vec{D}$ usual. Nevertheless, the lack of a sustained fall in $\mathbb{D}$ blood pressure after a bolus of adenosine indicated $\frac{\bar{T}}{\Phi}$ that it may be of particular use in infants and children $\frac{\pi}{3}$ with poor cardiac output when most other anti- $\mathbb{D}$ arrhythmic agents would be contraindicated. The $\vec{\overrightarrow{ }}$ one child who received a continuous infusion of $\mathscr{O}$ adenosine while under general anaesthesia did show a decrease in blood pressure and heart rate corresponding to the observations of Biaggioni and colleagues ${ }^{26}$ and this hypotension limited its therapeutic value.

In junctional tachycardias (atrioventricular reentry, atrioventricular nodal reentry, and long $\left.R-P^{\prime}\right) \stackrel{\varnothing}{\varnothing}$ we achieved an immediate termination of $86 \%$ of $\overrightarrow{\overrightarrow{0}}$ episodes and this was sustained in $75 \%$. Reinitiation 3 of supraventricular tachycardia may limit the clinical efficacy of this agent. A possible mechanism for this effect is the sinus acceleration that follows a bolus dose. This is a common mechanism of initiation of supraventricular tachycardia in small infants. ${ }^{27} \mathrm{~A} \frac{?}{\mathrm{\sigma}}$ further explanation is that the heart rate increases as a 3 result of central sympathetic activation as a reaction 8 to unpleasant side effects, which in adults are accep- $\frac{3}{3}$ table because they are transient. ${ }^{1}$ Interestingly, 웅 Overholt et al did not comment on this phenomenon and reported a $100 \%$ success rate in such arrhythmias. ${ }^{12}$ This may be because many of their children were either sedated or receiving a general anaesthetic $O$ at the time of adenosine administration. Although N efficacy was limited in some children by immediate $\mathrm{CU}_{\mathrm{N}}$ reinitiation of tachycardia, the short half life had major advantages in other respects; side effects were inevitably shortlived and repeated administration in $\frac{}{\Phi}$ those children with rapidly recurring supraven- $\stackrel{?}{?}$ tricular tachycardia was safe. We used adenosine in 0 conjunction with oral amiodarone, disopyramide, $\stackrel{\circ}{\circ}$

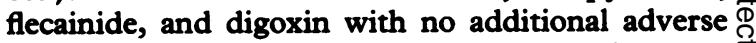
effects and believe it may prove useful in the man- $\mathbb{\nabla}$ agement of recurrent tachycardia in patients already 
being treated with other antiarrhythmic agents when adequate therapeutic concentrations had not yet been achieved.

We showed that adenosine was a safe agent in the treatment of paediatric supraventricular tachycardia and rapidly terminated most episodes. It was highly effective in junctional tachycardias and was safe to use in other less common arrhythmias. It offers many advantages in terms of its diagnostic and treatment successes and adverse effects over presently available drugs for the treatment of childhood supraventricular tachycardia, but therapeutic efficacy may be limited in some cases by rapid reinitiation of supraventricular tachycardia.

\section{References}

1 DiMarco JP, Sellers DT, Lerman BB, Greenberg ML, Berne RM, Bellardini J. Diagnostic and therapeutic use of adenosine in patients with supraventricular tachyarrhythmias. J Am Coll Cardiol 1985;6:417-24.

2 Rankin AC, Rae AP, Oldroyd KG, Cobbe SM. Verapamil or adenosine for supraventricular tachycardia [Abstract] Br Heart J 1989;61:123.

3 Clarke B, Till J, Rowland E, Ward DE, Barnes PJ, Shinebourne EA. Rapid and safe termination of supraventricular tachycardia in children by adenosine. Lancet 1987;i:229-301.

4 Bar FW, Brugada P, Dassen WR, Wellens HJ. Differential diagnosis of tachycardia with narrow $Q R S$ complex (shorter than 0.12 seconds). Am J Cardiol 1984;54:555-60.

5 Belardinelli L, Fenton RH, West A, Linda J, Althaus JS, Berne RM. Extracellular action of adenosine and the antagonism by aminophylline on the AV conduction of isolated perfused guinea pig and rat hearts. Circ Res 1982;51:569-79.

6 Watt A, Routledge PA. Adenosine: an importance beyond ATP. Br Med J 1986;293:1455-6.

7 Belhassen B, Pelleg A. Electrophysiologic effects of adenosine triphosphate and adenosine on the mammalian heart: clinical and experimental aspects. $J$ Am Coll Cardiol 1984;4:414-24.

8 Somlo E. Adenosine triphosphate in paroxysmal tachycardia [Letter]. Lancet 1955;268:1125.

9 Latour H, Puech P, Grolleau R, Sat M, Balmes P. L'utilisation de l'adenosine-5-triphosphorique dans le diagnostic et le traitement des tachycardies paroxystiques. Arch Mal Coeur 1968;61:293.

10 Burnstock $G$. A basis for distinguishing two types of purinergic receptors. In Bolis L, Straub RW, eds. Cell membrane receptors for drugs and hormones; $a$ multidisciplinary approach. New York: Raven, 1978:107-18.

11 Rankin AC, Rae AP, Oldroyd KG, Chong E, Cobbe SM. Adenosine or adenosine triphosphate for supraventricular tachycardia [Abstract]. Circulation 1988;78(suppl II):500.
12 Overholt ED, Rheuban KS, Gutgesell HP, Lerman BB, Dimarco JP. Usefulness of adenosine for the treatment of arrhythmias in infants and children. $A m J$ Cardiol 1988;61:336-40.

13 Perelman MS, Krikler DM. Termination of focal atrial tachycardia by adenosine triphosphate. Br Heart $J$ 1987;58:528-30.

14 Woodrow Berson D, Dunnigan A, Benditt DG, et al. Prediction of digoxin treatment failure in infants with supraventricular tachycardia: role of transoesophageal pacing. Pediatrics 1985;75:288-93.

15 Greco R, Musto B, Arienzo V, Alborino A, Garofalo S, Marsico F. Treatment of paroxysmal supraventricular tachycardia in infancy with digitalis, adenosine-5'-triphosphate and verapamil: a comparative study. Circulation 1982;66:504-8.

16 Shahar E, Barzilay Z, Frand M. Verapamil in the treatment of paroxysmal supraventricular tachycardia in infants and children. J Pediatr 1981;98:323-7.

17 Soler-Soler J, Sagrista-Sauleda J, Cabrera A, et al. Effect of verapamil in infants with paroxysmal supraventricular tachycardia. Circulation 1979;59: 876-9.

18 Belhassen B, Glick A, Laniado S. Comparative clinical and electrophysiologic effects of adenosine triphosphate and verapamil on paroxysmal reciprocating junctional tachycardia. Circulation 1988;77:795-805.

19 Garson A. Medicolegal problems in the management of cardiac arrhythmias in children. Pediatrics 1987;79:84-8.

20 Epstein ML, Kiel EA, Victorica BE. Cardiac decompensation following verapamil therapy in infants with supraventricular tachycardia. Pediatrics 1985;75: 737-40.

21 Kirk CR, Gibbs JL, Thomas R, Radley-Smith R, Qureshi SA. Cardiovascular collapse after verapamil in supraventricular tachycardia. Arch Dis Child 1987;62:1265-82.

22 Skovranek J, Ostadal B, Pelouch V, Prochazka J. Ontogenic differences in cardiac sensitivity to verapamil in rats. Pediatr Cardiol 1986;7:25-9.

23 Bucknall CA, Ladusans EJ, Tynan MJ, Curry PVL. Improved prognosis and treatment for children with His bundle tachycardia [Abstract]. Circulation 1985;72(suppl III):340.

24 Griffith MJ, Linker NJ, Ward DE, Camm AJ. Adenosine in the diagnosis of broad complex tachycardia. Lancet 1988;i:672-5.

25 Sollevi A, Lagerkranser M, Irestect L, Gordon E, Linquist C. Controlled hypotension with adenosine in cerebral aneurysm surgery. Anesthesiology 1984;661:400-5.

26 Biaggioni I, Olafsson B, Robertson RM, Hollister SA, Robertson D. Cardiovascular and respiratory effects of adenosine in conscious man. Evidence for chemoreceptor activation. Circ Res 1987;61:779-86.

27 Dunnigan A, Benditt DG, Woodrow BD. Modes of onset ("initiating events") for paroxysmal atrial tachycardia in infants and children. Am $J$ Cardiol 1986;57:1280-7. 